\title{
Signifikansi Konsep Christian Nurture Menurut Horace Bushnell Bagi Keluarga Kristen
}

\author{
Vardik Vandiano \\ Prodi Pasca Sarjana, Universitas Kristen Indonesia Jakarta \\ vardiklim.vl@gmail.com
}

\begin{abstract}
Christian Nurture is a Christian parenting concept that is applied in a family setting. The Christian Nurture pattern was introduced by a pastor named Horace Bushnell who lived in the 19th century, he emphasized the importance of a legacy of faith that is passed on to the next generation. In this 21 st century, does the family still play a role in guiding children to God? or whether this nurturing task has been delegated to the church so that the clergy are responsible for the development of the faith of the youth. According to Bushnell parents and the church should strive for the development of the faith of young people. Bilangan Research Center (BRC) in its research in 2018 found that parents who become true followers of Christ produce young people who find their purpose in life in God, have fellowship with God, do not easily give up, have big dreams and are confident to achieve the dream. Busnell based the concept of Christian Nurture based on Ephesians 6: 4 "... educate them in the teachings and counsel of God." Furthermore, in Proverbs 22: 6, it says "Educate a young person according to the way that is proper for him, so that at old age he will not deviate from that path." Busnell argues that there is an organic relationship between parents and children, the relationship in question is the role of parents as pillars who guide children to love and know God's commands. Busnell's concept is strengthened by the text quoted from Deuteronomy 7: 9 "Therefore you must know that God, Your God, He is God, a faithful God, who keeps His covenant and loyal love towards those who love Him and keep His commandments, to the thousands of descendants. "And the similar ideas that underlie the concept of Christian Nurture can be seen clearly from the faith Timothy passed down from his family. "Because I am reminded of your sincere faith, which is the faith that first lived in your grandmother Lois and in your mother Eunice and which I am sure lives also in you. (2 Tim. 1: 5). Some of the above texts convinced Busnell that in a parent who is faithful to God there is a life of strength and piety that is properly channeled to the offspring. This research was conducted using a qualitative approach, namely library studies. Through this paper, the author offers a thought about the concept of Christian nurture according to Horace Bushnell in the family sphere.

Keywords: e-Mission, Application, Evangelism, Technology
\end{abstract}

\begin{abstract}
Abstrak
Christian Nurture adalah sebuah konsep pengasuhan Kristen yang diterapkan dalam sebuah lingkup keluarga. Pola Christian Nurture diperkenalkan oleh seorang pendeta yang bernama Horace Bushnell yang hidup pada abad 19, ia menekankan pentingnya warisan iman yang diturunkan bagi generasi berikutnya. Di abad 21 ini, apakah keluarga masih memainkan peranan dalam membimbing anak-anak kepada Tuhan? ataukah tugas pengasuhan ini telah didelegasikan kepada gereja sehingga para rohaniawanlah yang bertanggungjawab atas perkembangan iman para kaum muda. Menurut Bushnell seharusnya orangtua dan gereja mengupayakan perkembangan iman kaum muda. Bilangan Research Center (BRC) dalam penelitiannya pada tahun 2018 menemukan bahwa orangtua yang menjadi pengikut Kristus yang sungguh-sungguh menghasilkan generasi muda yang menemukan tujuan hidupnya di dalam Tuhan, memiliki persekutuan dengan Tuhan, tidak mudah putus asa, memiliki mimpi besar serta keyakinan untuk meraih mimpi tersebut.Busnell mendasari konsep Christian Nurture berdasarkan Surat Efesus 6:4 “...didiklah mereka di dalam ajaran dan nasihat Tuhan." Selanjutnya dalam Amsal 22:6, dikatakan "Didiklah orang muda menurut jalan yang patut baginya, maka pada masa tuanyapun ia tidak akan menyimpang dari pada jalan itu." Busnell berpendapat bahwa adanya hubungan organis antara orangtua dan anak, hubungan yang dimaksud adalah peranan orangtua sebagai
\end{abstract}


sokoguru yang membimbing anak untuk mengasihi dan mengenal perintah Allah, konsep Busnell diperkuat dengan teks yang dikutip dari Ulangan 7:9 "Sebab itu haruslah kauketahui, bahwa TUHAN, Allahmu, Dialah Allah, Allah yang setia, yang memegang perjanjian dan kasih setia-Nya terhadap orang yang kasih kepada-Nya dan berpegang pada perintah-Nya, sampai kepada beribu-ribu keturunan." Serta gagasan serupa yang mendasari konsep Christian Nurture terlihat jelas dari iman Timotius yang diwariskan dari keluarganya. "Sebab aku teringat akan imanmu yang tulus ikhlas, yaitu iman yang pertama-tama hidup di dalam nenekmu Lois dan di dalam ibumu Eunike dan yang aku yakin hidup juga di dalam dirimu. (2 Tim. 1:5)." Beberapa teks di atas meyakinkan Busnell bahwa dalam diri orangtua yang setia kepada Tuhan sedang hidup suatu kekuatan dan kesalehan yang disalurkan secara benar kepada keturunannya. Penelitian ini dilakukan dengan menggunakan pendekatan kualitatif, yakni studi perpustakaan. Melalui tulisan ini, penulis menawarkan sebuah pemikiran tentang konsep pengasuhan Kristen menurut Horace Bushnell dalam lingkup keluarga.

Kata Kunci: Signifikasi, Christian Nurture, Keluarga, Kristen

\section{PENDAHULUAN}

Pada mulanya Allah menciptakan Adam dan Hawa dengan tujuan agar dapat terciptanya sebuah keluarga di atas bumi (Kej. 1:26-28; 2:21-25). Allah memberikan mandat kepada orangtua untuk mendidik setiap anak agar beriman dan menyembah Allah serta memuliakan-Nya. Selanjutnya Allah memberikan perintah kepada orangtua agar mengajarkan ketetapan Tuhan secara berulang-ulang kepada anak-anaknya (Ul. 6:6-7). Konsep pengasuhan ini, disebut shema Israel, yakni pembentukkan iman dan karakter anak di dalam konteks keluarga.

Pada tahun 1861, Horace Bushnell menerbitkan buku yang berjudul Christian Nurture yang menekankan pengasuhan iman dalam lingkup keluarga Kristen. Ia sangat menekankan peranan penting orangtua dalam mengasuh iman anak-anaknya. Pengasuhan Kristen bagi kaum muda di era globalisasi cenderung diberikan kepada para ahli yang menggelutinya. Dewasa ini, pola pembentukkan iman dan karakter diserahkan kepada gereja yang dianggap ahli dalam mengasuh iman dan karakter kaum muda. Tentu saja sikap tersebut merupakan sebuah hal yang baik dalam pelaksanaan pengajaran dasar iman, tetapi seharusnya orangtua juga bertanggung jawab atas pertumbuhan iman anak-anaknya. Di Alkitab terdapat contoh konkret tentang keluarga yang mewariskan iman kepada keturunannya. Pertumbuhan iman Timotius adalah hasil dari intervensi orangtuanya. Ia bertumbuh melalui neneknya yang bernama Lois dan ibunya Eunike (2 Tim. 1:5). Teladan iman yang diwariskan tersebut menghasilkan dasar iman yang kokoh bagi pertumbuhan iman Timotius. Oleh karena itu, pentingnya menerapkan pola Christian Nurture dalam lingkup keluarga.

Dalam tulisan ini, penulis akan membahas konsep Christian Nurture menurut Horace Bushnell dan hasil Penelitian yang ditemukan oleh $B R C$ serta kaitannya dengan pertumbuhan spiritualitas kaum muda melalui pengasuhan Kristen yang dilakukan oleh orangtua.

\section{HASIL DAN PEMBAHASAN Riwayat Hidup}

Horace Bushnell lahir pada tanggal 14 April 1802 di Bantam, Connecticut dan meninggal di Hartford pada 17 Februari 1876. Bushnell bertumbuh di kalangan Methodist dan ibunya seorang Episcopal, tetapi keduanya menjadi anggota gereja Kongregasional New Preston, Connecticut. Connecticut adalah kota tempat Bushnells 
pindah ketika Horace berusia tiga tahun. ${ }^{1}$ Di sana Bushnell bertumbuh menjadi dewasa serta mengaku beragama Kristen pada tahun 1821. Dalam sebuah tulisan tertanggal 3 Maret 1822, Bushnell mencatat pengalaman yang dia miliki pada saat dia bergabung dengan gereja: dia telah "dituntun kepada Yesus."2

Pada tahun 1823, ia memasuki Universitas YALE. Dia sangat dipengaruhi oleh filsuf penyair Inggris Samuel Taylor Coleridge, yang merasa bahwa kekristenan terutama dapat dipahami dengan intuisi. ${ }^{3}$ Setelah lulus pada tahun 1827 , ia mengajar di Norwich, Connecticut dan jurnalis di New York City, hal tersebut dilakukan hanya untuk meyakinkan diri bahwa keduanya bukan panggilannya. Awal tahun 1829, ia kembali ke Yale untuk belajar hukum, dan ia segera menjadi tutor di kampus. Pada tahun 1831, terjadi kebangunan rohani di Universitas Yale sehingga mengubah cara pandang Bushnell. ${ }^{4}$ Pada tahun yang sama ia memasuki Yale Divinity School dan setelah lulus pada 1833 ia dipanggil oleh Kongregasi Utara di Hartford dan dia melepaskan semua tugas pastoral di Kongregasi Utara pada 1859.

Ada beberapa karya yang dihasilkan oleh Bushnell, yakni: kumpulan Kotbah yang berjudul Kemelut Dalam Gereja yang terbit pada tahun 1835. Setahun kemudian ia menerbitkan artikel yang berjudul Kebangunan Rohani Dalam Agama. ${ }^{5}$ Pada tahun 1849 Bushnell mengeluarkan sebuah karya berjudul God in Christ yang berisi tentang klaim bahwa inkarnasi dan Trinitas adalah kebenaran dari pengalaman Kristen. ${ }^{6}$ Tahun 1859, ia menerbitkan kumpulan kotbah yang berjudul Kotbah Bagi Kehidupan Baru. ${ }^{7}$ Pada tahun 1861, ia mengarang sebuah buku yang berjudul Christian Nurture yang terkenal hingga saat ini. penulis menggunakan buku Christian Nurture sebagai acuan pandangan berpikir tentang pengasuhan Kristen dalam keluarga.

\section{Christian Nurture Menurut Horace Bushnell}

Anak yang dibesarkan dalam keluarga Kristen tidak hanya cenderung menyerap kesalehan yang diwariskan oleh orangtuanya, tetapi yang lebih penting adalah Allah menyuruh orangtua memberi bimbingan agar anak tersebut berbuat demikian. Perintah tersebut tersirat dalam Amsal 22:6, yakni "Didiklah orang muda menurut jalan yang patut baginya, maka pada masa tuanyapun ia tidak akan menyimpang dari pada jalan itu." Boehlke menyebutkan bahwa perintah tersebut bernuansa lahiriah, namun di dalamnya terkandung makna rohani, karena Perjanjian Lama tidak membedakan antara kehidupan batiniah dan yang lahiriah. ${ }^{8}$ Hal senada dapat ditemukan dalam Surat Efesus, Paulus menasihatkan kepada bapak-bapak di Efesus agar jangan membangkitkan amarah di dalam hati anak-anakmu, tetapi didiklah mereka di dalam ajaran dan nasihat Tuhan (Ef. 6:4).

'Elmer L Towns, (ed), A History Of Religious Educator, Elmer Town Online Library, 201.

2Elmer L Towns, (ed), 201.

3lbid., 201.

4lbid., 201. 2016), 443.

${ }^{5}$ Robert R. Boehlke, Sejarah Perkembangan Pikiran dan Praktek Pendidikan Agama Kristen (Jakarta: BPK Gunung Mulia,

${ }^{6}$ EImer L Towns, (ed), A History Of Religious Educator, 201.

${ }^{7}$ Robert R. Boehlke, Sejarah Perkembangan Pikiran dan Praktek Pendidikan Agama Kristen, 444.

${ }^{8}$ Robert R. Boehlke, 468. 
Hubungan organis antara anak dan orangtua sebagai sokoguru bagi Bushnell diperkuat oleh nats yang mencatat bagaimana Allah meneruskan berkat-berkat-Nya melalui orangtua yang saleh. TUHAN, Allahmu, Dialah Allah, Allah yang setia, yang memegang perjanjian dan kasih setia-Nya terhadap orang yang kasih kepada-Nya dan berpegang pada perintah-Nya, sampai kepada beribu-ribu keturunan, tetapi terhadap diri setiap orang dari mereka yang membenci Dia, Ia melakukan pembalasan dengan membinasakan orang itu. Ia tidak bertangguh terhadap orang yang membenci Dia. Ia langsung mengadakan pembalasan terhadap orang itu (Ul. 7:9-10). Oleh karena itu, pentingnya memiliki orangtua yang saleh sehingga dapat meneruskan berkat Tuhan bagi generasi seterusnya.

Gagasan serupa juga mendasari tinjauan berikut tentang iman yang pertamatama hidup dalam nenekmu Lois dan di dalam ibumu Eunike dan yang aku yakin juga hidup juga di dalam dirimu (1 Tim. 1:5). Boehlke berpendapat bahwa iman Kristen tidak disampaikan turun temurun seperti harta benda, namun ayat-ayat seperti di atas meyakinkan Bushnell bahwa dalam diri orangtua yang setia kepada Tuhan sedang hidup suatu kekuatan dan kesalehan yang disalurkan secara wajar kepada anak-anaknya. ${ }^{9}$

Bushnell memulai argumentasinya dengan memaparkan dalilnya yang ia pertahankan melalui seluruh isi bukunya. Dalilnya adalah Bahwa anak akan bertumbuh menjadi orang Kristen dan tidak pernah mengetahui bahwa dirinya adalah orang yang sebaliknya. ${ }^{10}$ Dengan kata lain, tujuan, upaya, dan harapan bukan seperti asumsi pada umumnya, bahwa anak mulanya bertumbuh dalam dosa sehingga bertobat saat mencapai usia dewasa, tetapi anak harus terbuka pada dunia sebagai orang yang diperbarui secara spiritual sehingga sejak masa kecil ia mengenal dirinya sebagai orang yang memihak pada hal-hal baik. ${ }^{11}$

Tesis yang diungkapkan Bushnell bertentangan dengan pihak revivalis yang menolak kemungkinan untuk mendidik anak dalam Tuhan sebelum bertobat. Menurut Robert Boehlke, pola Christian Nurture bertujuan untuk menanamkan bibit iman Kristen dalam diri anak, supaya anak tersebut memegang nilai-nilai kristiani secara wajar dan semakin mengabdikan diri kepada Allah dalam Yesus Kristus, tanpa harus mengalami pergumulan rohani. ${ }^{12}$ Bushnell tidak menolak kenyataan pertobatan bagi orang yang tidak dibesarkan dalam keluarga Kristen, ia menghormati kebebasan Roh Kudus. Oleh karena itu, ia menolak untuk memutlakkan hanya satu cara saja yang tersedia untuk mengalami anugerah Allah. ${ }^{13}$

Bushnell memanfaatkan dua sumber utama untuk mempertahankan dalilnya tentang arti pendidikan Kristen, yakni pengalaman anak yang dibesarkan dalam keluarga Kristen dan metode-metode yang Allah berlakukan. ${ }^{14}$ Tidak ada ajaran Alkitab yang mengajarkan bahwa anak harus menolak segala sesuatu yang berasal dari Allah sampai

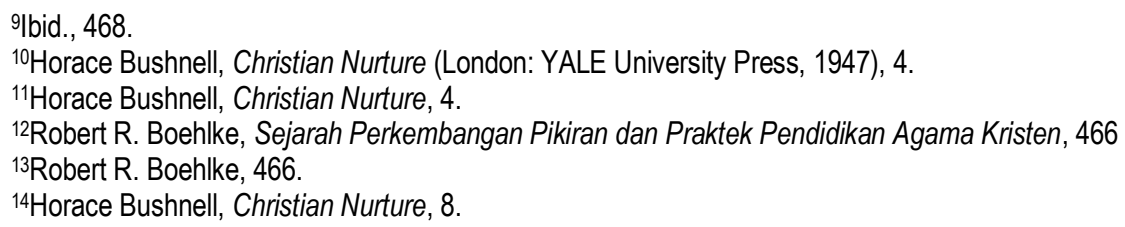


ia dapat bertobat ketika menginjak dewasa. ${ }^{15}$ Lebih lanjut Bushnell mengajukan pertanyaan yakni dengan wewenang apakah orang berhak mendorong anak merasa bahwa ia adalah orang yang paling tidak beruntung, karena ia mampu melakukan dosa, tetapi tidak mampu bertobat sehingga cukup tua untuk menolak semua kebaikan, tetapi terlalu muda untuk menerima kebaikan dalam bentuk apa pun? Boehlke berpendapat bahwa ada banyak kasus yang membuktikan kemampuan anak untuk mengikuti kepercayaan dan nilai-nilai yang dipercaya oleh orangtuanya. ${ }^{16}$ Hal senada diungkapkan oleh James Fowler dalam teori tahapan perkembangan iman yang menemukan bahwa anak pada tahap Intuitive-Projective Faith dipengaruhi oleh contoh, suasana hati, perilaku, dan tindakan-tindakan iman yang kelihatan dari orang dewasa, terutama dari orangtua. ${ }^{17}$ Jadi, pada masa anak-anak, keluarga memiliki peranan penting dalam perkembangan iman. Oleh karena itu, orang dewasa/orangtua berkewajiban memberikan teladan dan pengajaran iman kepada mulai dari kanak-kanak.

Adanya perbedaan antara pendidikan Kristiani dan non-Kristiani. Pengasuhan Kristen memiliki tujuan yang lebih tinggi dan karakter yang lebih mulia serta orangtua Kristen juga mengalami pengasuhan dari Tuhan. Jadi, baik orang tua dan anak mengalami proses pengasuhan dari Tuhan. Oleh karena itu, kasih Allah layak dikomunikasikan melalui orangtua yang telah mengalami lahir baru. ${ }^{18}$ Selanjutnya Bushnell mengajukan pertanyaan bahwa lebih baik membiarkan anak bertumbuh tanpa bimbingan atau mengasuh anak-anak berdosa dalam kesalehan menurut Alkitab? Jawaban dari pertanyaan tersebut, yakni mengasuh anak-anak berdosa dalam kesalehan menurut Alkitab, karena mulai dari kecil seharusnya anak-anak diperkenalkan tentang keselamatan kekal yang hanya terdapat dalam Tuhan Yesus. ${ }^{19}$

Sejak semula Allah menginginkan sebuah warisan iman yang diturunkan orangtua kepada anak, karena Allah membenci dosa sehingga Allah menginginkan pola pengasuhan iman dalam keluarga. Tindakan Allah dalam memperlengkapi orangtua untuk mengasuh iman anak-anaknya yakni dengan mencurahkan Roh Kudus dan hidup yang dipenuhi oleh Roh Kudus serta mempertimbangkan hubungan organik antara anak dan orangtua sehingga orangtua mampu mengasuh anak dengan prinsip Alkitab. ${ }^{20}$

\section{Hasil Penelitian BRC tentang Spiritualitas Generasi Muda dalam Keluarga}

Hasil penelitian Bilangan Research Center (BRC) terhadap dinamika spiritualitas generasi muda Kristen di Indonesia ini mengungkapkan bahwa kedalaman spirittualitas orangtua, kesungguhan dalam mengikuti Tuhan Yesus, bagaimana Ayah dan ibu memperlakukan anak-anaknya (tidak pilih kasih) serta investasi orangtua untuk hadir (seutuhnya) dan berjalan bersama dengan anak-anaknya di usia remaja dan

15|bid., 8.

${ }^{16}$ Robert R. Boehlke, Sejarah Perkembangan Pikiran dan Praktek Pendidikan Agama Kristen, 467.

${ }^{17}$ James W. Fowler, Stages Of Faith (The Psyhology Of Human Development And The Quest For Meaning), (New York: HarperCollins Publisher, 2011), 133.

18Horace Bushnell, Christian Nurture, 10.

19|bid., 12.

20Horace Bushnell, 25. 
pemuda, terbukti memiliki keterkaitan yang sangat kuat dengan pertumbuhan spiritualitas generasi muda. ${ }^{21}$

Remaja dan pemuda Kristen yang dibesarkan oleh orangtua yang merupakan pengikut Kristus yang sejati, menjalankan kepemimpinan bersama yang efektif dalam keluarga, terlibat aktif dalam pelayanan gerejawi, menyediakan waktu yang berkualitas, penuh kepedulian yang tulus dan sungguh-sungguh atas hidup dan minat mereka, serta membangun komunikasi dua arah yang terbuka dan sehat dengan anak-anaknya, cenderung menghasilkan generasi muda yang menemukan tujuan hidup di dalam Tuhan Yesus, yang memiliki persekutuan akrab dengan Tuhan, tidak mudah putus asa dan yang memiliki mimpi yang besar serta keyakinan untuk meraih mimpi tersebut. ${ }^{22}$

Penelitian juga membuktikan bahwa orangtua yang sering meluangkan waktu untuk mendiskusikan hal-hal rohani dengan anak remaja dan pemudanya, cenderung menghasilkan generasi muda yang taat Firman Tuhan, khususnya berkaitan dengan Amanat Agung Tuhan Yesus, yaitu bersaksi, memberitakan Injil dan membimbing atau memuridkan teman-teman dan adiknya dalam menolong pertumbuhan rohani mereka.

\section{Hubungan Christian Nurture dengan Pertumbuhan iman Kaum Muda}

Berdasarkan pembahasan di atas, penulis menemukan hubungan yang erat antara pola pengasuhan Kristen di dalam keluarga dengan pertumbuhan iman kaum muda. Keluarga adalah wadah terdekat yang dimiliki oleh anak-anak sehingga orangtua/orang dewasa memainkan peranan penting dalam mengasuh iman anak-anaknya dan menjadi teladan dalam kehidupan sehari-hari. Berikut ini adalah hubungan Christian Nurture dengan pertumbuhan iman kaum muda, yaitu sebagai berikut:

1. Orangtua/orang dewasa yang telah mengalami pengasuhan dari ayah/ibu dan bimbingan Roh Kudus akan mengalami pertumbuhan iman serta dapat menerapkan hidup saleh dihadapan Tuhan dan menjadi teladan bagi generasi berikutnya

2. Orangtua yang telah mendapat pola pengasuhan Kristen, secara spontan akan mewariskan imannya kepada keturunan berikutnya sehingga anak-anak generasi mendatang memiliki warisan iman yang serupa dari orangtua mereka

3. Pentingnya Quality Time dalam kerangka Christian Nurture bersama seluruh anggota keluarga sehingga terjalin hubungan yang harmonis antara anggota keluarga, karena anak-anak mengharapkan kepedulian dari orangtua/orang dewasa di sekitarnya. Keberadaan dan kepedulian orang dewasa kepada anak dapat mempermudah pelaksanaan pola asuh Kristen

4. Orangtua yang aktif dalam melayani Tuhan di gereja memilki berpengaruh positif pada perkembangan kegiatan religius anak

5. Pentingnya membangun mezbah dalam sebuah keluarga sehingga anak-anak dapat meneladani spiritualitas dari orangtuanya ketika berada di rumah. Jadi kegiatan rohani bukan hanya dilaksanakan di gereja, tetapi juga di dalam keluarga/di rumah. 


\section{KESIMPULAN}

Berdasarkan pembahasan di atas dapat dismpulkan bahwa keluarga memiliki peranan penting dalam mengasuh kerohanian anggota keluarganya. Pelaksanaan pola asuh Kristen dalam keluarga akan menghasilkan fondasi yang kokoh dalam kehidupan spiritulitas serta melalui penerapan pola asuh tersebut akan menghasilkan sikap saling peduli terhadap satu dengan yang lainnya. Oleh karena itu, orangtua/orang dewasa seharusnya tidak mendelegasikan tugas pengasuhan iman kepada gereja secara sepenuhnya, karena orangtua/orangdewasa berada pada lingkup yang paling dekat dengan anak-anaknya sehingga yang memiliki peranan penting dalam mengasuh iman kerohanian anak adalah orangtua/orang dewasa.

\section{KEPUSTAKAAN}

Bushnell, Horace, Christian Nurture, London: YALE University Press, 1947.

Boehlke, Robert R., Sejarah Perkembangan Pikiran dan Praktek Pendidikan Agama Kristen, Jakarta: BPK Gunung Mulia, 2016.

Elmer L Towns, (ed), A History Of Religious Educator, Elmer Town Online Library. Fowler, James W., Stages Of Faith (The Psyhology Of Human Development And The Quest For Meaning), New York: HarperCollins Publisher, 2011.

Groome, Thomas, Christian Religous Education, Jakarta: BPK Gunung Mulia, 2018. Pudjianto, Bambang, Dinamika Spiritualitas Generasi Muda Kristen Indonesia, Jakarta: Yayasan BRC, 2018. 